Karina Nalevaiko Rocha ${ }^{1}$

Solange Muglia Wechsler ${ }^{2}$

\title{
CRIATIVIDADE NAS ORGANIZAÇÕES: DA CONCEPÇÃO ÀS FORMAS DE AVALIAÇÃO
}

\begin{abstract}
Resumo
Crescentemente as empresas precisam ser inovadoras para manterem-se no mercado, e diante da importância da criatividade nesse processo, fazem-se necessárias técnicas e ferramentas que possibilitem a sua identificação. Este estudo objetivou entender qual é a concepção sobre a criatividade entre os psicólogos organizacionais, se ela é avaliada e quais as ferramentas ou técnicas utilizadas. A amostra foi composta por 50 psicólogos que atuam na área de Recursos Humanos. Constatou-se que os profissionais de RH reconhecem a importância da criatividade e há uma concepção alinhada às teorias atuais. No entanto, a forma como a criatividade tem sido avaliada nas empresas suscita algumas discussões. A predominância pela Entrevista e Dinâmica de Grupo e o pouco uso de testes pode estar negligenciando aspectos importantes da avaliação. Desse modo, são necessários maiores estudos que contemplem as temáticas de técnicas de seleção fundamentais para apoiar o trabalho de profissionais dessa área.
\end{abstract}

Palavras chaves: criatividade; processo seletivo; recursos humanos.

\section{CREATIVITY IN ORGANIZATIONS: FROM THE CONCEPTION TO THE FORMS OF EVALUATION}

\begin{abstract}
Increasingly companies need to be innovative to stay in the market, and given the importance of creativity in the process, are necessary techniques and tools that allow their identification. This study aimed to understand what the conception of creativity among organizational psychologists, if it is evaluated and what tools or techniques. The sample consisted of 50 psychologists working in the area of Human Resources. It was found that HR professionals recognize the importance of creativity and there is a design aligned to current theories. However, how creativity has been evaluated in a few succinct business discussions. The prevalence for Interview and Group Dynamics and the little use of tests may be overlooking important aspects of evaluation. Therefore, it should be further studies that address the issues of selection techniques is fundamental to support professionals working in this area
\end{abstract}

Keywords: creativity; selective process; Human Resources.

(1) Mestre em Psicologia pelo Programa de Pós Graduação em Psicologia da PUC Campinas (SP) kanalevaiko@gmail.com

(2) Professora do Programa de Pós Graduação em Psicologia da PUC Campinas (SP) wechsler@lexxa.com.br. 


\section{INTRODUÇÃO}

Atualmente, as empresas estão cada vez mais preocupadas e somando esforços no sentido de serem inovadoras, pois segundo Rodrigues \& Veloso (2013) inovar é hoje, um imperativo para as organizações. Para uma empresa se manter competitiva no mercado global, ela necessita de estratégias baseadas em inovações e requer capacidades internas em constantes e intensas transformações (PAROLIN, 2013). Assim, a magnitude e a velocidade das transformações no mercado exigem decisões rápidas para fatos novos, para os quais não se podem utilizar padrões pré-estabelecidos, havendo a necessidade de criar-se novas alternativas e soluções (MAGALHÃES \& ALENCAR, 2001; ALENCAR, 1995). Assim sendo, é crescente, pertinente e atual o interesse por estudos sobre a criatividade e é compreensível que indivíduos, grupos e organizações estejam bastante preocupados com a temática (RIBEIRO, 2009).

Há uma estreita relação entre inovação e criatividade, mesmo tratando-se de conceitos diferentes. A criatividade tem muitos conceitos, mas, é consenso que a estrutura fundamental do fenômeno criativo são as ideias criativas e quando aplicadas, teriam a capacidade de promover a inovação de estruturas, estratégias e processos organizacionais (BEDANI, 2012). Segundo Wechsler (2011), toda inovação começa com ideias criativas, pois a implementação bem-sucedida de novos programas, novos produtos ou serviços depende que seus colaboradores tenham uma boa ideia. Assim, a inovação decorre da implementação de ideias criativas (BRUNO-FARIA, 2003) e seria, portanto, a produção de ações frente à criação de ideias (POZZEBON, et. al, 2011).

A criatividade é o desejo de criar, mas que precisa ser transformada em inovação, ou seja, tornando as ideias criativas em produtos, serviços, processos ou métodos operacionais (PAROLIN, 2008). Assim, a inovação é a implementação eficaz das ideias que provêm da criatividade (AMABILE, CONSTANCE \& STEVEN, 2002) evidenciando que a criatividade é uma condição necessária para que a inovação ocorra com sucesso (MARKS \& HUZZARD, 2008).

Nas empresas, a criatividade é transformada em valor econômico, ou seja, postula-se que a criatividade contribui para a produtividade, competitividade e sobrevivência organizacional (BENDASSOLLI, 2009). Atualmente, onde a regra nas organizações passou a ser a mudança, diferente da concepção de estabilidade citada pelos economistas neoclássicos, a criatividade passa a ter destaque e importância crescente, sendo uma competência desejada, onde as empresas estão buscando-a e empenhando-se a incorporá-la na cultura das empresas (FONSECA \& BASTOS, 2003).

No entanto, as organizações muitas vezes acabam por dificultar e impedir a criatividade, mostrando barreiras que podem ser estruturais, sociais e políticas, processuais, de recursos e individuais (ALENCAR \& FLEITH, 2003). É muito difícil para a empresa criar um ambiente estimulador à criatividade, sendo mais frequente que a criatividade seja sufocada e minada por estruturas rígidas e padrões de trabalho únicos (AMABILE, 1999). Esse é um aspecto observado também em outros contextos, como a a área educacional, segundo Wechsler (2001) a criatividade ainda é um fenômeno pouco implementado nas escolas, embora seja importante e possa ser aplicada a qualquer disciplina, o professor tem dificuldades em implementar ideias criativas e estimular a criatividade dos alunos, seja por deficiências em sua formação, desconhecimento de técnicas, procedimentos e metodologias incentivadoras da criatividade, seja pela extensão do currículo a cumprir, geralmente busca-se a resposta certa, não oportunizando o novo e o diferente.

Historicamente a criatividade não despertava interesse científico e não era sequer uma característica desejável, em geral, era associada às artes e por sua vez, com pessoas com estereótipos e comportamentos estranhos, indicando algumas desordens e problemas psicológicos, como por exemplo Da Vinci, Van Gogh entre outros e, assim, a ideia de 
"genialidade" e "loucura" estavam muito relacionadas (WECHSLER, et al, no prelo). A criatividade era entendida sob um aspecto subjetivo e sob esse ponto de vista não era passível de investigação, até o século XVII predominou a perspectiva subjetiva e que conferia à criatividade explicações de genialidade, inspiração e sorte (PINHEIRO \& CRUZ 2009). $O$ enfoque místico e a ideia de que a criatividade era algo destinado apenas a um grupo seleto de pessoas, possivelmente algo inato e inexplicável, também atribui a ideia de que não poderia ser desenvolvida e assim, nada poderia ser feito no sentido de estimulá-la ou promovê-la (SCHLEDER 1999). A influência da teoria evolucionista também reforçou esta ideia, quando entendia-se que a criatividade era transmitida pelos códigos genéticos, estando fora do controle, portanto, não educável (WECHSLER, 2008).

A criatividade tem sido estudada e definida de diversas maneiras, desde 1950 já se encontravam mais de 100 definições de criatividade na literatura científica (MORAIS \& AZEVEDO, 2009), o que sugere a existência de um fenômeno complexo, com múltiplas facetas (RUNCO, 2004). Sabe-se que a criatividade envolve a definição e redefinição de problemas (Lubart, 2007) relacionado ao aperfeiçoamento de ideias "antigas" trazendo uma perspectiva inovadora, ou ainda, um rompimento com o passado, emprestando o que já se conhece a novos contextos (Sutton, 2002) e produzindo alguma contribuição valiosa (Bruno-Faria, 2003), aceito como útil por um indivíduo ou um grupo de pessoas (FISCHER \& AMABILE, 2009). Existem diferentes estudos sobre o tema criatividade que permitem entendê-la como um constructo de diferentes perspectivas. Assim, a criatividade é considerada como uma característica da pessoa, como um processo, como parte de um contexto e também, como uma capacidade extraordinária para resolver problemas, em geral, a criatividade tem sido definida como a geração de novas ideias e conceitos, novas relações entre ideias e conceitos conhecidos, que normalmente produzem soluções ou produtos originais e valiosos para uma sociedade (PRIETO, SOTO \& VIDAL, 2013).

Diante da natureza complexa e polifacetada, avaliar a criatividade constitui-se um grande desafio, cumprindo um importante papel na busca da objetividade no entendimento do pensamento criativo (MORAIS \& AZEVEDO, 2009). A avaliação da criatividade segue por 2 linhas pesquisa: a quantitativa e a qualitativa, onde a qualitativa tem sido utilizada através de entrevistas livres, observações e a biografia de pessoas que tiveram e destaque social e receberam reconhecimento público pelo seu feito e na linha quantitativa a avaliação é realizada através de instrumentos padronizados, precisos e fidedignos (WECHSLER, 2009).

Assim sendo, mensurar a criatividade cumpre papel importante ao buscar objetividade no entendimento da criatividade, tendo sua importância em vários âmbitos. A avaliação da criatividade é extremamente relevante, pois auxilia na identificação e desenvolvimento de talentos humanos, favorece a compreensão da natureza do potencial humano, é uma linha de base para assessorar na orientação de professores no processo de ensino-aprendizagem, permite dados aos pesquisadores de pré e pós teste para avaliar se houve melhora à partir de uma intervenção, auxilia na identificação de talentos e permite que o conceito saia do campo do mistério e da superstição (MUNDIM, et. al., 2014; FLEITH \& ALENCAR, 1992). Bahia (2007), também reforça a importância em avaliar a criatividade e argumenta que, apesar de todas as críticas relativas a instrumentos que avaliam a criatividade, apesar de paradoxal, complexa, limitada e totalmente reducionista, a avaliação da criatividade é necessária em diversos contextos, quer de avaliação ou intervenção.

Muitas pesquisas têm sido realizadas e estudos nacionais e internacionais reforçam que além da importância de mensurar a criatividade este é um constructo que pode ser medido de forma a atender os padrões científicos para instrumentos psicológicos de validade e precisão (WECHSLER \& NAKANO, 2011). Garcia, Gomes e Torrano (2013), salientam que os testes psicométricos seguem sendo os instrumentos mais utilizados para estudar a criatividade sendo os mais úteis e válidos atualmente. Também Pinheiro (2013) acrescenta que o uso de testes 
de criatividade é e continuará sendo uma excelente forma de saber mais e mais a respeito das pessoas criativas e do próprio fenômeno em si, essas medidas contribuem não apenas costurando os conhecimentos já existentes, mas também proporcionando outros, inéditos.

É consenso entre muitos autores a importância e necessidade da avaliação psicológica (Noronha, 2002), porém, avaliações ineficientes impactam negativamente na comunidade científica e na sociedade, denigram a profissão do psicólogo (Machado, 2000) em vários contextos, mais especificamente nas organizações, uma avaliação inadequada traz prejuízos ao processo de empregabilidade, vagas deixam de ser preenchidas, contrata-se candidatos que não possuem o perfil adequado à função, empresa e candidatos ficam frustrados (Pereira, Primi \& Cobêro, 2003), contribuindo para o desemprego e oneração dos processos seletivos.

Para que as empresas possam suprir às novas demandas, os empresários optam por inovação e recursos humanos mais criativos (Perez, 2005) e buscam na seleção a forma de maximizar o capital intelectual (PEDROSO \& CINTRA, 2010). O recrutamento e seleção são essenciais à organização e orientam políticas de Recursos Humanos, pois nenhuma política de RH será satisfatória se o processo de seleção não o for (ANDRADE, 2009). A contratação de funcionários em uma empresa, assim como outras atividades, é parte do negócio, que quando bem executadas transformam gastos em lucros (CAPPELLI, 2010). Em um estudo longitudinal realizado com 750 empresas americanas, Watson Wyatt World Wide no Canadá concluíram que investimentos em recrutamento e seleção e retenção de talentos podem aumentar o valor da empresa no mercado (BATES, 2001).

Anteriormente buscava-se "a pessoa certa no lugar certo", já hoje, em uma dimensão mais estratégica, a preocupação deixa de ser o nível micro para voltar-se para o macro da organização, cuja preocupação é "a pessoa certa para a empresa certa" (MARRAS, 2005). Extrapola-se portanto, os limites de um cargo para uma estrutura organizacional mais ampla, cujo principal determinante no processo seletivo deixa de ser a qualificação e experiência anterior do candidato e predomina o potencial de desenvolvimento e suas competências individuais, buscando-se assim, profissionais sintonizados com os objetivos a longo prazo da organização. A preocupação na busca de capital humano no mercado de trabalho não pode mais ser vista e feita como era proposto no tempo em que o funcionário era contratado apenas para preencher um determinado cargo e responder somente pelas atividades pré determinadas (PEDROSO \& CINTRA, 2010).

Entende-se por processo seletivo, no contexto organizacional, o uso de procedimentos de avaliação e informações estrategicamente planejados que objetivam identificar dentre os candidatos aqueles que melhor se integrarão ao perfil desejado do cargo, à cultura vigente e as expectativas (atuais e futuras) da organização (GOULART JUNIOR, 2003). Os testes psicológicos são considerados ferramentas essenciais para a seleção de pessoal, porém este assunto levantado muitas discussões acerca de sua validade (PEREIRA, PRIMI \& CORBERO, 20013). Não existem testes específicos para cada profissão, portanto, não se sabe se há validade científica nessa prática (PASQUALLI, 1999). Em uma pesquisa realizada por Godoy \& Noronha (2005) constatou-se que poucos profissionais utilizam testes nos processos seletivos e conhecem poucos instrumentos, o que pode ser justificado por variáveis como a defasagem na formação profissional, baixa qualidade psicométrica de muitos instrumentos, ausência de estudos de validade para os diferentes contextos profissionais, alto custo de alguns instrumentos, entre outros.

Geralmente são utilizadas diversas técnicas de seleção que variam de acordo com o perfil e complexidade dos cargos e, quanto maior o número de técnica de seleção, maior será o número de informações para a seleção e maior será a chance de ter êxito na escolha (ALMEIDA, 2009). Segundo Benucci (2003) não só a entrevista é importante no processo seletivo, mas testes psicológicos, dinâmicas de grupo entre outros, são instrumentos 
importantes para alcançar um maior índice de acerto nas contratações. Segundo Canisian (2002) os testes psicológicos ajudam o psicólogo a traçar o perfil do candidato, no entanto, as entrevistas e dinâmicas de grupo são instrumentos importantes e necessários, devendo fazer parte de um conjunto de informações, conferindo-lhe maior segurança na tomada das decisões. Segundo Santos et al (2003) a dinâmica de grupo é muito utilizada e trata-se de uma ferramenta útil para o processo de seleção, pois nessa técnica poderá ser observado padrões de comportamento compatíveis ao esperado. A seleção por competências é uma alternativa que tem-se mostrado viável, sendo possível acessar o repertório comportamental de candidatos (Alencar, 2007) e a dinâmica pode ser uma técnica eficaz na seleção por competências.

Geralmente o processo seletivo é composto por algumas fases como atração, triagem, avaliação e decisão (ALMEIDA, 2008). Em geral, a dinâmica de grupo antecede à etapa de entrevista, o que muitas vezes assume um caráter eliminatório, portanto, uma vez que competências não são avaliadas nessa etapa, pode-se comprometer todo o processo seletivo. Esse um motivo de grande preocupação, pois observa-se que na prática instrumentos subjetivos de avaliação, como a entrevista e dinâmica de grupo, têm substituído gradativamente o uso de testes psicológicos, oportunizando que qualquer profissional possa realizar a seleção (CANISIAN, 2002), correndo riscos de uma avaliação errônea.

A dinâmica de grupo é uma técnica vivencial bastante utilizada e tem como objetivo criar um clima descontraído, promover a interação do grupo, propiciar condições para o relacionamento interpessoal, observar atitudes frente à criatividade, iniciativa, persuasão, liderança, entre outros. É uma técnica muito interessante, pois permite contato com o comportamento do indivíduo dentro de uma rede de relações com os outros candidatos, com a situação problema, os recursos, etc (PARPINELLI \& LUNARDELLI, 2006). É uma técnica de integração de pessoas e no contexto organizacional é considerada uma ferramenta que auxilia o processo de seleção, entretanto não deve ser usada isoladamente, pois não existem estudos de validade dessa técnica, uma vez que não é um teste, mas uma técnica que permite observar o candidato em uma ação, chamada de role-playing (PEREIRA, PRIMI \& CORBERO, 2003). Há estudos internacionais com job simulation e que demonstram uma validade maior se combinado essa técnica com medidas cognitivas (Schmidt e Hunter, 1998), assim, novos funcionários seriam melhor selecionados se fossem utilizados dois instrumentos ao invés de um só (PEREIRA, PRIMI \& CORBERO, 2003). Assim sendo, o uso de testes e dinâmica de grupo, sucedida de entrevista pode ser um modelo eficaz nos processos seletivos.

Estudos têm demonstrado que a criatividade atende a parâmetros de uma disciplina científica, podendo ser identificada e desenvolvida (WECHSLER, 2009). Porém, estudos referentes à criatividade geralmente concentram-se nas áreas da educação, e mesmo assim, faltam instrumentos validados que apóiem as estratégias de ação do profissional e lhe confiram maior cientificidade (WECHSLER \& NAKANO, 2011). Atualmente há apenas 3 instrumentos aprovados pelo Satepsi, sendo eles o Testes Verbal e Figural de Torrance (2002), Estilos de Criar e Pensar (2006) e Teste de Criatividade Figural Infantil (2010). Portanto, existe a necessidade de mais instrumentos que avaliam a criatividade no Brasil.

Considerando que estudar a criatividade no contexto organizacional, buscando maneiras de identificar, estimular e desenvolver a criatividade é fundamental, o presente trabalho objetivou entender qual é a concepção sobre a criatividade mais adotada entre os psicólogos organizacionais, se ela é avaliada e quais as ferramentas ou técnicas utilizadas nesta avaliação. 


\section{MÉTODO:}

\section{Participantes:}

Participaram da pesquisa 50 profissionais que atuam ou atuaram em Recursos Humanos nas cidades de Campinas $(n=25)$, Curitiba $(n=20)$ e grupos de RH à nível Brasil $(n=5)$, sendo $96 \%(n=48)$ dos participantes do sexo feminino. As idades variaram de 27 a 55 anos, sendo a média de idade de 35,6 anos. Em relação a escolaridade 100\% eram graduados em Psicologia e $90 \%(n=45)$ tinham pelo menos Pós Graduação na área. Ocupavam posição de liderança à nível de supervisão, coordenação, gerência e diretoria $26 \%(n=13)$ dos participantes.

\section{Material:}

Questionário de Percepção da Criatividade:

Este questionário foi composto por 11 perguntas fechadas sobre a criatividade. As perguntas abordaram os seguintes aspectos: 1) interesse pelo tema 2) relevância da criatividade no contexto onde atua ou atuava 3) leitura sobre o assunto 4) concepções sobre o que é uma pessoa criativa 5) concepção se a criatividade pode ser desenvolvida 6) concepção da empresa em relação à pessoa criativa 7) necessidade de avaliação da criatividade no contexto de atuação 8) ferramentas e técnicas utilizadas para avaliação 9) perfil da empresa 10) concepção da empresa sobre pessoas criativas 11) escala para mensurar qual o nível de importância da criatividade em uma escala de 0 a 10, sendo 0 não importante e 10 muito importante.

Solicitou-se que os participantes indicassem 1 resposta para cada pergunta, afim de verificar qual é a concepção predominante. No entanto, o ítem 4 referente à concepções sobre pessoas criativas, alguns participantes podiam assinalar mais de 1 alternativa.

\section{Procedimento:}

Após aprovação do Comitê de Ética de pesquisas da PUC Campinas da linha de pesquisa em Avaliação Psicológica, os sujeitos receberam um e-mail explicando os objetivos da pesquisa, a forma como seria conduzida e informações da sua participação, sendo esta de livre consentimento. Em alguns casos, o primeiro contato foi realizado por telefone e os contatos posteriores foram realizados por e-mail. Após o convite para participação na pesquisa, pediuse para aqueles que optassem pela participação para que enviassem um aceite por e-mail. Enviou-se então, um segundo e-mail com um questionário com questões fechadas.

\section{RESULTADOS}

Quanto ao interesse pelo tema criatividade, observou-se que $98 \%(n=49)$ dos entrevistados tem interesse pelo tema e $84 \%(n=42)$ já leram algo sobre o assunto. Importante notar que $20 \%(n=10)$ acessaram literatura internacional sobre o assunto. Constatou-se que $96 \%(n=48)$ consideram a criatividade relevante no contexto em que atuam.

Solicitou-se que os participantes dessem uma nota de 0 a 10 do quanto consideravam a importante a criatividade, sendo 0 não importante e 10 extremamente importante. A média referente a estas notas atribuídas à importância da criatividade foi 8,22 , esse dado demonstra que o tema tem despertado interesse crescente.

As concepções acerca do que é uma pessoa criativa podem ser observadas na tabela 1 
Tabela 1- Concepções sobre uma pessoa criativa $(n=50)$

\begin{tabular}{lll}
\hline Concepção & $\mathbf{N}$ & $\mathbf{\%}$ \\
$\begin{array}{l}\text { Uma pessoa com ideias inovadoras e aplicáveis, sendo } \\
\text { úteis e gerando benefícios. }\end{array}$ & 29 & $58 \%$ \\
$\begin{array}{l}\text { Uma pessoa com facilidade em identificar e resolver } \\
\text { problemas em vários contextos }\end{array}$ & 20 & $40 \%$ \\
$\begin{array}{l}\text { Pessoa que tem sempre muitas ideias , mesmo que não as } \\
\text { coloca em prática }\end{array}$ & 6 & $12 \%$ \\
$\begin{array}{l}\text { Um artista } \\
\text { Uma pessoa inteligente }\end{array}$ & 2 & $0,50 \%$ \\
$\begin{array}{l}\text { Uma pessoa que tem um dom, uma dádiva divina } \\
\text { Uma pessoa estranha e que destoa da normalidade }\end{array}$ & 0 & $0,50 \%$ \\
Uma pessoa mais ligada às áreas de Marketing, Criação, & 0 & $0 \%$ \\
Artes etc. & 0 & $0 \%$ \\
\hline
\end{tabular}

Alguns participantes optaram por mais de uma alternativa. Como pode ser observado, constatou-se que a concepção predominante acerca de uma pessoa criativa refere-se àquela que tem ideias inovadoras e aplicáveis, sendo úteis e gerando benefícios, apontada 29 vezes representando $58 \%$ das respostas. Em segundo lugar, representando $40 \%$, refere-se à pessoa criativa aquela com facilidade em identificar e resolver problemas em vários contextos. Com menor expressão, $12 \%$ citam que a pessoa criativa é uma pessoa que tem sempre muitas ideias, mesmo que não as coloque em prática. A concepção de que a pessoa criativa é um artista ou uma pessoa inteligente foi considerada por $1 \%$ dos entrevistados.

Outro dado relevante na pesquisa é que além de considerar a criatividade importante no contexto em que atua, $96 \%(n=48)$ entrevistados acreditam que a criatividade pode ser desenvolvida. É possível perceber como os profissionais de recursos humanos percebem o espaço que as empresas dão às pessoas criativas. Estes dados são apresentados na Tabela 2.

Tabela 2- Percepção dos profissionais de $\mathrm{RH}$ em relação ao posicionamento da empresa frente às pessoas criativas. $(n=50)$

\section{Considerações sobre a pessoa criativa}

Considera que na sua empresa as pessoas criativas são valorizadas e promovidas

\section{$\%$}

$44 \%$

$34 \%$

Considera que sua empresa procura pessoas criativas

Considera que as pessoas criativas tem dificuldades em colocar suas idéias em prática

Mencionou que na sua empresa as pessoas não são valorizadas ou não são bem vistas na empresa.

Total
$41 \%$

$100 \%$

Observa-se nessa tabela que $44 \%$ dos participantes responderam que na sua empresa as 
pessoas criativas são valorizadas e promovidas, $34 \%$ consideram que sua empresa procura pessoas criativas. Assim, 78\% considera que a criatividade é vista positivamente na sua empresa. Consideram que pessoas criativas tem dificuldades em colocar em prática suas idéias $21 \%$ dos participantes e $1 \%$ relatam que as pessoas criativas não são bem vistas ou valorizadas na empresa.

Em relação ao perfil das empresas dos participantes, $46 \%(n=23)$ consideram sua empresa com uma postura mais inovadora e $48 \%(n=24)$ consideram sua empresa com uma postura mais conservadora e tradicional e $6 \%(n=3)$ não souberam responder ou não consideraram sua empresa nem inovadora, nem tradicional.

Quanto à necessidade de avaliação da criatividade, observa-se que $82 \%(n=41)$ dos profissionais já precisaram avaliar a criatividade no seu trabalho, porém o uso de testes é muito pequeno, podendo ser considerado inexpressivo ( $1 \%$ da amostra). Quanto às técnicas de avaliação mais citadas, os resultados são apresentados na Tabela 3.

Tabela 3. Técnicas e Ferramentas para avaliação da criatividade nas organizações.

\begin{tabular}{lll}
\hline Técnica & N & $\mathbf{\%}$ \\
Dinâmica de Grupo e Entrevista & 22 & $53 \%$ \\
Dinâmica de Grupo & 9 & $21 \%$ \\
Entrevista & 7 & $17 \%$ \\
Testes projetivos & 1 & $3 \%$ \\
Teste Human Guide & 1 & $3 \%$ \\
Entrevista e Avaliação do Portfólio & 1 & $3 \%$ \\
& & \\
Total & 41 & $100 \%$ \\
\hline
\end{tabular}

Constata-se que $82 \%$ dos profissionais já avaliou a criatividade em seu contexto de trabalho. As técnicas e ferramentas mais citadas foram a Dinâmica de Grupo e Entrevista, representando $53 \%$ das formas de avaliação mencionadas pelos participantes. A dinâmica de grupo representa $21 \%$ e a Entrevista $17 \%$. Somente $6 \%$ utilizam algum instrumento. Os instrumentos para avaliação psicológica mencionados foram Testes Projetivos e Human Guide de Rolf Kenmon (1999), com estudos de evidências de validade para a realidade brasileira conduzidos no trabalho de mestrado de Welter (2007).

\section{CONCLUSÃO}

A presente pesquisa pode constatar que a criatividade tem sido crescentemente valorizada e despertado o interesse entre os profissionais de Recursos Humanos, corroborando com dados da literatura, que afirma que a criatividade tem despertado interesse crescente em várias áreas (WECHSLER, 2009; PINHEIRO \& PINHEIRO, 2005; ALENCAR, 1986).

$\mathrm{Na}$ área de Recursos Humanos, o interesse de $98 \%$ dos profissionais pela temática pode estar relacionado com a grande expressão que a criatividade ocupa nas empresas, o que também corrobora com dados da literatura que entendem que a criatividade é transformada em valor econômico (Brendassolli et. al., 2009), ou seja, o sucesso e desenvolvimento de uma empresa dependem diretamente de novas ideias e propostas para manter-se competitiva (WECHSLER, 2014).

Referente ao contexto em que atuam, a maioria dos entrevistados relatam que consideram a criatividade relevante, ou seja, a criatividade é importante para o desenvolvimento do seu 
trabalho. Esse dado é representativo, consolida e fundamenta que a criatividade é um tema considerado importante e relevante para Psicólogos que atuam na área de Recursos Humanos. Esses dados corroboram com a literatura que descrevem que na área de Recursos Humanos a preocupação crescente é a de promover a inovação de estruturas, estratégias e processos organizacionais, e nesse sentido, a criatividade torna-se fundamental (BEDANI, 2012).

Abusca por mais conhecimentos sobre o tema também é relevante e o contato inclusive com literatura internacional indica um enriquecimento no nível destas informações. A necessidade identificada no seu contexto de trabalho, no seu dia a dia têm motivado os profissionais a buscarem maiores informações sobre o assunto (MAGALHÃES \& ALENCAR, 2001). Assim sendo, estes dados indicam que pesquisas voltadas à criatividade no contexto organizacional, buscando maneiras de identificá-la, estimulá-la e desenvolvê-la é fundamental (FLEITH \& ALENCAR, 1992).

Em relação às concepções acerca do que é uma pessoa criativa, observa-se uma predominância pelas repostas que relacionam à criatividade a facilidade na resolução de problemas, tendo ideias inovadores e aplicáveis, considerando assim, a criatividade útil e geradora de benefícios. Esse dado demonstra um grande avanço na temática, pois representa uma ruptura com a representatividade negativa da criatividade. Relacionava-se a criatividade com loucura, associando a artistas como Da Vinci, Van Gogh entre outros e assim, não era uma característica desejável (WECHSLER, no prelo). Até o século XVII predominou a perspectiva subjetiva e que conferia à criatividade explicações de genialidade, inspiração e sorte (PINHEIRO\& CRUZ, 2009), assim, os dados demonstram rupturas nestes paradigmas que imperaram por muitos anos, inclusive no meio científico, acarretando prejuízos, desinteresse pelo tema e um atraso nos estudos sobre a criatividade (LUBART, 2007).

Uma matéria publicada na Veja, revista de grande circulação nacional, na edição de dezembro de 2014 contempla 19 páginas dedicadas sobre criatividade. Isso indica que o senso comum também tem demonstrado interesse crescente pela temática e reconhece a importância da criatividade e sua representatividade positiva, entendendo que ela é importante para a melhoria e desenvolvimento da sociedade. Desta forma, os profissionais têm uma concepção alinhada aos conceitos atuais. Preito, Soto \& Vidal (2013) consideram a criatividade como uma capacidade extraordinária para resolver problemas, a geração de novas ideias e conceitos, produzem soluções ou produtos originais e valiosos para uma sociedade. Assim sendo, a presente pesquisa constatou que os profissionais de recursos humanos entendem a criatividade como positiva, necessária e geradora de benefícios.

Não só a importância da criatividade é nitidamente expressa pelos participantes como também a concepção de que a criatividade pode ser desenvolvida, representada pela maioria dos participantes. Muitas pesquisas têm sido realizadas e indicam que a criatividade é um construto mensurável e passível de intervenções (WECHSLER \& NAKANO, 2011). Assim, a concepção mencionada nas empresas indica que o interesse pela criatividade pauta-se nas suas possibilidades de desenvolvimento dentro das empresas. Esse é um dado relevante que fundamenta ainda mais avanços importantes na temática. $O$ enfoque místico e a ideia de que a criatividade era algo destinado apenas a um grupo seleto de pessoas, possivelmente algo inato e inexplicável, também atribui a ideia de que não poderia ser desenvolvida e assim, nada poderia ser feito no sentido de estimulá-la ou promovê-la (SCHELEDER 1999). A influência da teoria evolucionista também reforçou esta ideia, quando entendia-se que a criatividade era transmitida pelos códigos genéticos, estando fora do controle, portanto, não educável (WECHSLER, 2008). Assim, o fato dos profissionais reconhecerem a possibilidade de intervenções na empresa, no sentido de desenvolver a criatividade é um grande ganho para a área, fundamenta os avanços positivos e importantes para a temática, estando alinhando com as concepções atuais, onde considera-se que grande parte do comportamento criativo é aprendida e pode ser estimulada (FLEITH, 2007). 
A pesquisa demonstrou que a maioria das empresas procuram, valorizam e promovem pessoas criativas, o que indica uma mudança importante nas empresas. Porém estudos indicam que mesmo que a empresa reconheça e busque profissionais criativos, a empresa não oferece um ambiente estimulador para a criatividade (ALENCAR \& FLEITH, 2003). Esse dado é expresso por um terço da amostra, que entendem que a pessoas criativas têm dificuldades em colocar suas idéias em prática ou são mal vistas. Esse contrassenso corrobora com a literatura e relaciona-se com outros contextos, como a área educacional, que indica que alunos criativos não tem possibilidades de expressar-se na escola e ainda, não são bem vistos por terem ideias originais e não se adaptarem ao modelo escolar tradicional onde busca-se somente a resposta certa (WECHSLER, 2001). Assim, futuros estudos que contemplem as características de um ambiente facilitador e maneiras de desenvolvimento da criatividade nas empresas é de grande importância.

Uma vez que as concepções acerca da criatividade foram investigadas e verificou-se que ela é considerada muito importante e relevante para as empresas, uma segunda preocupação deste estudo pauta-se então, em como a criatividade tem sido avaliada nas empresas. Sabese que a avaliação psicológica cumpre um importante papel no levantamento de dados, precedendo uma intervenção (NORONHA, 2002), portanto, a conduta do profissional pode ter grandes benefícios embasando-se em dados científicos. A presente pesquisa mostrou que grande parte dos profissionais já precisaram avaliar a criatividade, porém apenas $1 \%$ utilizou algum teste. Os testes citados foram Human Guide (2005) e testes projetivos. Referente ao teste Human Guide, segundo o SATEPSI, encontra-se validado desde 2007 para uso e aplicação no Brasil, é multidimensional e entre os 8 itens que propõem avaliar considera o fator imaginação. No entanto, nenhum dos 2 testes validados no Brasil que avaliam a criatividade em adultos, Testes Verbal e Figural de Torrance (2002), Estilos de Criar e Pensar (2006) foram mencionados.

Esses dados são de extrema importância para pesquisadores e estudiosos da área, pois posto está um desafio: a necessidade de construção e validação de novos instrumentos que avaliem este construto no contexto organizacional. Outro aspecto corrobora com os dados da literatura, que cita o pouco uso de instrumentos psicológicos na seleção de pessoas. Em estudo realizado por Godoy \& Noronha (2005) e Noronha (1999) que confirmam que o uso de teste é restrito a uma parcela de profissionais. Atribui-se este fato à muitos fatores, entre eles deficiências na formação profissional, baixa qualidade psicrométrica dos testes e alto custo de alguns materiais. Assim, outros desafios à área são evidentes e merecem maior atenção.

Constatou-se que a Entrevista e Dinâmica de Grupo foram as técnicas mais citadas e, estes dados corroboram com a literatura, em estudo realizado por Godoy \& Noronha (2005) que relata que as técnicas mais utilizadas nos processos seletivos nas organizações são entrevista, dinâmica de grupo, nessa ordem. No presente estudo, outra forma de avaliar a criatividade citada foi utilizar a entrevista e analisar o produto criativo, neste caso um portfólio das criações do candidato para vagas na área de Marketing. As formas de avaliação também trazem dados importantes, uma vez que a predominância pela Entrevista e Dinâmica de Grupo e o pouco uso de testes pode estar negligenciando aspectos importantes da avaliação que poderiam ser melhores trabalhados e identificados com a combinação destas técnicas e algum instrumento psicológico (PEREIRA, PRIMI \& CORBERO, 2003).

Esses dados são relevantes e significativos, pois permitem uma maior reflexão para a área de avaliação psicológica e o trabalho do psicólogo. A preocupação acerca da avaliação permeia o fato de que a grande maioria dos entrevistados avalia a criatividade através da entrevista e dinâmica de grupo, o que implica uma avaliação baseada na subjetividade, não demonstrando atender a critérios científicos necessários. Os profissionais de recursos humanos demonstram não ter consciência da importância da cientificidade das avaliações e faltam parâmetros Dessa forma, no contexto atual, onde as seleções baseiam-se em 
competências sobrepondo-se à experiência e currículo profissional (MARRAS, 2005), pode-se incorrer a muitos erros que podem comprometer a seleção como um todo, gerando prejuízos para a empresa e incorrendo em injustiças com os candidatos avaliados (PEREIRA, PRIMI \& CORBERO, 2003). Assim, a Psicologia deve maiores estudos que contemplem avaliar a validade de técnicas de seleção é fundamental para apoiar o trabalho de profissionais dessa área.

Outra necessidade apontada pelo presente estudo é a importância de haver uma articulação maior entre teoria e prática, oportunizando ganhos para os dois contextos: academia e organizações, proporcionando avanços, fomentando novos estudos, gerando discussões e proporcionando um melhor entendimento em relação ao tema criatividade.

Diante da importância da criatividade no mundo atual, onde tanto empresas com um perfil mais inovador como também empresas com perfil mais conservador indicam que que necessitam de profissionais com perfil criativo, fazem-se necessárias técnicas e ferramentas que possibilitem a melhor identificação da criatividade visando estimulá-la e desenvolvêla em vários contextos. Na área organizacional, sua expressão é nítida, uma vez que está intimamente com a inovação, e inovar hoje é uma necessidade e um desafio para as empresas (RODRIGUES \& VELOSO, 2013). Assim, sugere-se maiores estudos que enfoquem esta temática, dada a relevância e importância do tema no contexto organizacional.

Este estudo considerou apenas a visão de psicólogos que atuam ou atuaram em recursos humanos, assim, novos estudos que contemplem outros grupos dentro das empresas como gestores e outros profissionais poderá trazer grandes contribuições ao tema. Sugere-se também estudos que abranjam outras regiões do país e não somente Sul e Sudeste, como predominante esta pesquisa considerou, ampliando a amostra sejam de grande importância. Também estudos que busquem analisar os comportamentos com instrumentos científicos nas avaliações da criatividade nas empresas, oportunizando uma melhoria nos processos seletivos podem delinear novos caminhos e contribuir com a prática profissional do psicólogo e agregar à ciência como um todo.

\section{Referências:}

ALENCAR, E.M.L.S. (1995). Desenvolvendo a criatividade nas organizações: o desafio da inovação. RAE Revista de Administração de Empresas, v. 35 (6). pp 6-11.

ALENCAR, E.M.L.S. (2005). Escala sobre o Clima para a Criatividade em Sala de Aula. Psicologia Teoria e Prática, 21 (1). pp. 85-91.

ALENCAR, E. M. L. S. . Criatividade (resenha). (2001). Boletim da Academia Paulista de Psicologia, São Paulo, 21, (4), pp. 27-30.

ALENCAR, E.T.S (2007). Recrutamento e Seleção: O que a Analise do Comportamento tem a Dizer? Retirado em 15 de novembro de 2014 do site: www.redepsi.com.br

ALENCAR, E. M. L. S., \& FLEITH, D. S. (2003). Criatividade: múltiplas perspectivas (3a. ed.) Brasília: EdUnB.

ALMEIDA, W. (2008) Capatação e seleção de talentos: repensando a teoria e a prática. São Paulo: Atlas, 2008

AMABILE, T., CONSTANCE N. H., \& STEVEN J. K. (2002). Creativity under the gun. Harvard Business Review, 80(8), pp. 52-61

AMABILE, T. M. (1999). Como não matar a criatividade. HSM Management, 3 (12), 110117.

ANDRADE, K.M. (2009). Práticas de recrutamento e seleção nas empresas. Psicologia 
IESB, 10, (10), pp. 1-10.

BAHIA, S. (2007). Quadros que compõem a criatividade: Uma análise do teste de Torrance. Sobredotação. pp. 91-120

BARLACH, L. (2009). A criatividade humana sob a ótica do empreendedorismo inovador. Tese de Doutorado. Instituto de Psicologia da Universidade de São Paulo. São Paulo, SP. 12.

BATES, S. (2001) Study links HR practices with the botton line. Alexandria: HR Magazine,

BEDANI, M. (2008). Valores, práticas e criatividade organizacionais: estudo do perfil cultural de uma instituição bancária. Tese de Doutorado - Universidade de Brasília. Brasília, DF.

BENDASSOLLI, P.F. et al, (2009). Indústrias criativas: definição, limites e possibilidades. RAE, São Paulo, v. 49, n 1.

BENUCCI, M. (2003). Entrevista e processo seletivo. Retirado em 10 de setembro de 2014 do site http://www.rh.com.br/

BRUNO-FARIA, M.F. (2003). Criatividade, inovação e mudança organizacional. In Lima, S.M.V. (org). Mudança Organizacional: teoria e gestão. Rio de Janeiro: FGV, p. 111-142.

CANISIAN, R. M. M. (2002). O psicólogo e seu espaço nas organizações. data. Retirado em 12 de setembro de 2014 do site : http://www.cjh.ufsc.br/sinapsi/artigos/organizacional3htm

ENMO, R. (2005). Let the Personality bloom - a blue thread towards life balance in your living-space. Stockholm: Författares Bokmaskin.

FISHER, C. \& AMABILE, T. M. (2009). Creativity, improvisation, and organizations. In T. Rickards, M. A. Runco, \& S. Moger (Orgs.), The Routledge Companion to Creativity. Oxford, UK: Routledge

FLEITH, D. S. (2007). A promoção da criatividade no contexto escolar. In A. Virgolim (Org.), Talento criativo: expressão em múltiplos contextos (pp.145-157). Brasília: EdUnB.tividade em estudantes normalistas. Estudos de Psicologia, 9, pp. 9-38.

GARCIA, C.F., GÓMEZ, M.S. \& TORRANO, D.H. (2013). Evaluación y Desarrollo de La Creatividad. In. Piske, F.H.R. \& Bahia, S. (orgs), Criatividade na escola: o desenvolvimento de potencialidades, altas habilidades / superdotação e talentos (pp. 51-68) Curitiba: Juruá.

GODOY, S.L. \& NORONHA, A.P.P. (2005). Instrumentos psicológicos utilizados em seleção profissional. Revista do Departamento de Psicologia UFF, v 17, nº 1, p 139-159.

GOULART JUNIOR, E. (2003). Avaliação psicológica em processos seletivos: uma análise da atuação do psicólogo em consultorias de recursos humanos da cidade de Bauru. (pp.1-71). Texto mimiografado.

LUBART, T. (2007). Psicologia da criatividade. Porto Alegre: Artmed.

MACHADO, A.P. (2000). Avaliação Psicológica e suas dimensões. Revista Contato, do

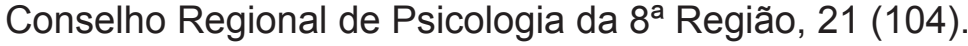

MAGAÇHÃES, M. G. M. S. ; ALENCAR, E. M. L. S. (2001). Criatividade e inovação em organizações públicas e privadas do Distrito Federal. Estudos Empresariais, Brasília, 6, (1), pp. 12-18.

MORAIS, M.F., \& AZEVEDO, I. (2009). Avaliação da criatividade como um contexto delicado: revisão de metodologias e problemáticas. Avaliação Psicológica, 2008, 8 (1) pp1-15.

MUNDIM, M.C.B.; MILLIAN, Q. G.; GUMS, E.F., WECHSLER, S.M., Damasceno, Y.S.L. (2014). Avaliação da criatividade em universitários. Revista Psicopedagogia, 31 (94). 
NAKANO. T.C., \& WECHSLER, S.M. (2012) Criatividade: definições, modelos e formas de avaliação. In C.S. Hutz (orgs). Avanços em avaliação psicológica e neuropesicológica de crianças e adolescentes (V.II, pp 327-362). São Paulo: Casa do Psicólogo.

NORONHA. A.P.P. (2002). Os problemas mais graves e mais frequentes no uso dos testes psicológicos. Psicologia: Reflexão e crítica, Porto Alegre, v.15, n. 1, p. 135-142.

PARPINELLI, R.F., LUNARDELLI, M.C. F. (2006). Avaliação psicológica em processos seletivos: contribuições da abordagem sistêmica. Estudos de Psicologia 23 (4), 463-471.

PASQUALLI, L. (Org.) (1999). Instrumentos psicológicos: manual prático de elaboração. Brasília: LabPAM; IBAPP.

RUNCO, A. \& MOGER, S. (Eds.), The Routledge Companion to Creativity. Oxford, UK: Routledge.

PERDOMO-ORTIZ, J., GONZALES-BENITO, J., \& GALENDE, J. (2009). An analysis of the relationship between total quality management-based human resource management practices and innovation. The international Journal of Human Resource Management, 20 (5), 1191-1218.

PEDROSO, R. \& CINTRA, G.A. (2010). Seleção de pessoal: influências dos comportamentos emocionais e seleção de repertório comportamental. Revista Olhar Científico - Faculdades Associadas de Ariquemes, 1, (1).

PELAES, M.L.W. (2010). Uma reflexão sobre o conceito de criatividade e o ensino da arte no ambiente escolar. Revista Educação. 5, (1). pp. 5-12.

PEREIRA, F.M., PRIMI, R.\& CORBERO, C. (2003). Validade de testes utilizados em seleção de pessoal segundo recrutadores. Revista Teoria e Prática. 5 (2), 83-98

PINHEIRO, I. (2013). Medindo a criatividade na escola e no mundo: a enterseção do conhecimento. Piske, F.H.R. \& Bahia, S. (orgs), Criatividade na escola: o desenvolvimento de potencialidades, altas habilidades / superdotação e talentos (pp. 97-112) Curitiba: Juruá.

POZZEBON, Marlei ; Petrini, M. ; Mello, R. B. ; Garreau, L. Unpacking researchers' creativity and imagination in grounded theorizing: Information and Organization, v. 21, p. 177193, 2011.

PREDEBON, J. (2001). Criatividade- abrindo o lado inovador da mente ( $3^{a}$ ed, p. 230). São Paulo: Atlas.

PREITO, M.D., SOTO, G. \& VIDAL, M.C.F. (2013). El aula como espacio creativo. Piske, F.H.R. \& Bahia, S. (orgs), Criatividade na escola: o desenvolvimento de potencialidades, altas habilidades / superdotação e talentos (pp. 33-50) Curitiba: Juruá.

RUNCO, M.A. (2004). Creativity. Annual Reviews os Psychology, 55: 657-687.

RUNCO \& JAEGER (2012). The standard definition of creativity. Creativity Research Journal, 24; 1, pp. 92-96.

SANTOS, J.G.W., FRANCO, R.N.A., MIGUEL, C.F. (2003). Seleção de pessoal: considerações preliminares sobre a perspctiva behaviorista radical. Psicologia: Reflexão e Crítica, 16 (2), 235-243.

SCHMIDT, F.L. ; HUNTER, I.E. (1998). The validity and utility os selection methods in personel psychology: pratical and theoretical implications of 85 years os research findings. Psychology Bulletin, v. 124, n.2.

SIMONTON, D.K. (2000). Creativity: cognitive, personal, developmental and social aspects. American Psychologist, 55 (1), 151-158.xdjrk76

STERNBERG, R.J., LUBART, T.L., KAUFMAN, J.C. \& PRETZ, J.E. (2005). Creativity. In 
K.J. Holyoak \& R. G. Morrison (Eds), The Cambridge handbook of thinking and reasoning (pp. 351-369). New York: Cambridge University Press.

SUTTON, R. (2002). Weird ideas that work: Practices for promoting, Managing and sustaining innovation.NY: Cambridge University Press. NY: The Free Press.

WECHSLER, S. M. (2001). A educação criativa: possibilidade para descobertas. In S. Castanho, S. \& M. E. Castanho (Orgs.), Temas e textos em metodologia do ensino superior (pp.165-170). Campinas: Papirus

WECHSLER, S.M. (2004a). Avaliação da criatividade por figuras. Teste de Torrance. Versão brasileira. Campinas: LAMP/PUC-Campinas.

WECHSLER, S.M. (2004b). Avaliação da criatividade por palavras. Teste de Torrance. Versão brasileira. Campinas: LAMP/PUC-Campinas.

WECHSLER, S.M. (2008) Criatividade descobrindo e encorajando ( $3^{\mathrm{a}}$ ed.). Campinas: LAMP/ PUC-CAMPINAS

WECHSLER, S.M. (2009) Avaliação da criatividade: possibilidades e desafios. In C.S. Hutz (org.), Avanços e polêmicas em avaliação psicológica (pp.93-125) São Paulo: Casa do Psicólogo.

WECHSLER, S.M. \& NAKANO, T.C. (2011). Criatividade:encontrando soluções para os desafios educacionais. In S.M. Wechsler \& V.L.T. (Orgs.). Criatividade e aprendizagem: caminhos e descobertas em perspectiva internacional (pp. 11-32). São Paulo: Edição Loyola.

WELTER, G. M. R. (2007). HumanGuide: Evidências de Validade da Versão Brasileira. Dissertação de Mestrado em Psicologia. Universidade São Francisco. Itatiba

WHO Instituto de pesquisa e opinião e mercado \& Conselho Federal de Psicologia (2001). Pesquisa de Opinião WHO - Quem é o psicólogo brasileiro. 